NBER WORKING PAPER SERIES

\title{
ENTRY DETERRENCE IN \\ HOSPITAL PROCEDURE MARKETS: A SIMPLE MODEL OF LEARNING-BY-DOING
}

\author{
Leemore S. Dafny \\ Working Paper 9871 \\ http://www.nber.org/papers/w9871 \\ NATIONAL BUREAU OF ECONOMIC RESEARCH \\ 1050 Massachusetts Avenue \\ Cambridge, MA 02138 \\ July 2003
}

I thank David Cutler, Glenn Ellison, Jonathan Gruber, and James Poterba for exceptional guidance. I am grateful to Julian Jamison, Michael Mazzeo and Scott Stern for helpful comments. Support from the National Science Foundation, the National Bureau of Economic Research, and the National Institute on Aging is gratefully acknowledged. The MedPAR data are confidential and cannot be released. The views expressed herein are those of the authors and not necessarily those of the National Bureau of Economic Research.

(C)2003 by Leemore S. Dafny. All rights reserved. Short sections of text, not to exceed two paragraphs, may be quoted without explicit permission provided that full credit, including $(\mathrm{C}$ notice, is given to the source. 
Entry Deterrence in Hospital Procedure Markets: A Simple Model of Learning-By-Doing Leemore S. Dafny NBER Working Paper No. 9871

July 2003

JEL No. L1, I2

\begin{abstract}
This paper examines the strategic behavior of hospitals in one of their primary output markets: inpatient surgical procedures. High levels of learning-by-doing in surgical fields may act as a barrier to entry. I investigate whether incumbent hospitals facing prospective entry in a procedure market manipulate their procedure volumes to produce such a barrier. I derive straightforward empirical tests from a model of patient demand, procedure quality, and differentiated product competition. Using hospital data on electrophysiological studies, an invasive cardiac procedure, I find evidence of entry-deterring investment in procedure volume. These findings suggest that competitive motivations may play a role in treatment decisions.
\end{abstract}

Leemore S. Dafny Department of Management and Strategy

Kellogg School of Management

Northwestern University

2001 Sheridan Road

Evanston, IL 60208

and NBER

1-dafny@kellogg.northwestern.edu 


\section{Introduction}

The hospital industry that has emerged after nearly two decades of cost-containment is both more efficient and more competitive. The survivors of the industry shakedown have adopted many traditional business practices, ranging from strict budgeting and heavy marketing to explicit collusion through affiliations with competitors. Whether hospitals engage in more sophisticated strategic decisionmaking, as well as the implications of such behavior, remain open questions. This paper investigates the use of one such practice: strategic investment for the purpose of entry deterrence.

The setting for this analysis is an inpatient surgical procedure market, such as the market for open heart surgery. Research has shown that providers with more experience produce better outcomes, and as this research has disseminated, information about physician and hospital experience levels has become more accessible. The high degree of learning-by-doing in many of these markets raises the possibility that learning-by-doing may act as a barrier to entry, as noted by Ho (2002) in a recent study of the diffusion of coronary angioplasty. I investigate whether incumbent hospitals facing prospective entry in a procedure market increase their procedure volume to produce such a barrier. Perhaps by creating a "center of excellence" in a given procedure market, hospitals can forestall new entrants, whose comparative lack of experience is unattractive to patients, physicians, and insurers alike.

The theory of strategic investment, in which an incumbent firm (the "first mover") adjusts its investment in period 1 because its choice affects play in period 2 , originates in Stackelberg (1934) and is extended by Spence (1977, 1979), Dixit (1979, 1980), and others. Several of these authors, notably Spence (1984) and Fudenberg and Tirole (1983, 1986), 
note the possibility of using experience for strategic effect. The opportunity to squeeze or even eliminate competitors by moving quickly along a firm-specific learning curve has not eluded businesses in several key industries; for example, it is widely reported that airplane manufacturers price below cost for the first several hundred units of a new design, a strategy that often succeeds in deterring or severely handicapping the entry of competing aircraft (Newhouse 1982).

Although inpatient surgical procedures are a primary output of the hospital industry, research on competition within surgical procedure markets - or even the concept of a surgical procedure market - is not well-developed. Several papers have explored the relationship between a hospital's decision to offer a particular service or surgery and the competitive environment in which it operates, but few have offered a structural interpretation of this relationship or provided a model of competitive play. ${ }^{1}$ In addition, the role of learningby-doing in surgery, though well-documented, has only been linked anecdotally to market structure. This paper formalizes these relationships by explicitly modeling the demand and supply for surgical procedures, incorporating the role of learning-by-doing into the production function, and positing a differentiated-products game that governs play among market participants. I use this model to illustrate the incentives for strategic investment in learning-by-doing, focusing on incumbents' ability to deter entry through this channel. To develop testable predictions, I use an approach presented in Ellison and Ellison (2000). Ellison and Ellison demonstrate that investment by incumbents facing entry should increase monotonically with market potential unless entry deterrence incentives are present. These

\footnotetext{
${ }^{1}$ Exceptions include Chernew, Gowrisankaran, and Fendrick (2002), who model entry into bypass surgery as a function of expected patient flows, and Vogt (1999), who considers preemption motives for acquisition of magnetic resonance imaging (MRI) machines in duopoly hospital markets.
} 
incentives are strongest in markets of intermediate attractiveness, where potential entrants are "on the fence" and are likeliest to be swayed by incumbents' actions. In the context of surgical procedure markets, where the investment is volume, the testable implication is that procedure growth should be strongest in markets of intermediate potential if hospitals attempt to deter entry.

Using nationwide data from MedPAR, the Medicare claims database, I investigate the relationship between the probability of entry and volume growth in local markets for electrophysiological studies (EP). I focus on incumbents' growth following the announcement of a reimbursement increase for EP in 1989. I find the strongest volume response among incumbent providers in markets facing intermediate ex-ante threats of entry. This crosssectional finding is confirmed in a panel analysis using data from 1985-1989. Controlling for incumbent fixed effects, year fixed effects, and time trends that vary by the probability of entry, I find that volume growth between 1988 and 1989 is statistically larger for incumbents in intermediate markets than for incumbents in markets with low or high ex-ante entry probabilities (48 and 44 percentage points larger, respectively). These point estimates imply a substantial impact of entry deterrence motives on hospital volumes for procedures characterized by a high degree of learning-by-doing.

The following section describes prior research on learning-by-doing in surgical procedures and strategic entry deterrence. In section 3, I draw on these literatures to develop a dynamic model of competition, and to derive empirically testable predictions that discern between strategic and non-strategic investment patterns. In Section 4, I test these predictions using hospital-level data on electrophysiological studies from 1985-1989. Section 5 concludes. 


\section{Background}

The model presented in Section 3 is based on two distinct literatures: medical research on learning-by-doing in surgery, and theoretical and empirical economic research on entry deterrence. I combine the results from these literatures, together with observations on hospital markets, to build a model of entry deterrence through learning-by-doing in surgical procedure markets.

\subsection{Learning-by-Doing in Surgery}

Since the late 1970s, medical researchers have published hundreds of articles investigating the relationship between surgical volume and patient outcomes. Although the strength of this relationship differs across studies, procedures, and outcome measures, the resounding conclusion from this research is that, for many procedures, there is a strong, positive correlation between procedure-specific hospital volume and outcomes, and this correlation is robust to detailed controls for patient risk factors, hospital characteristics, surgeon volume, and local sociodemographics.

Procedures with strong hospital volume/outcome relationships include coronary artery bypass surgery (CABG), cardiac catheterization, prostatectomy, total hip replacement, and resectioning of abdominal aortic aneurysms, to list only a few. Examples of procedures with weak or insignificant associations include cholecystectomy (gall bladder removal), inguinal hernia repair, and femur fraction reduction; these are all procedures that require less technical expertise to obtain successful outcomes. ${ }^{2}$ Although this evidence is suggestive of learning-

\footnotetext{
${ }^{2}$ The evidence on the relationship between surgeon volumes and outcomes is less conclusive, although there is consensus that a positive correlation is present for select procedures (e.g. carotid endarterectomy), and
} 
by-doing in surgery, there are a number of limitations of the medical literature that render such a conclusion premature. First, the outcome measures used in most studies - inpatient mortality, length of stay, and post-surgery complications - are extremely limited. Hospitals with low volumes are at greater risk for extremely high levels of these variables simply because of statistical chance. Second, although the studies attempt to control for patient risk factors, the potential for omitted variables is clearly problematic. Third, these studies cannot distinguish between two alternate hypotheses for the volume/outcome phenomenon: the "practice makes perfect" or learning-by-doing hypothesis, and the "selective referral" hypothesis, which maintains that hospitals with good outcomes generate high volumes, rather than vice-versa.

The few studies that have attempted to separate these effects have found support for both. Simultaneous-equation estimates of the outcome-volume relation and the volumeoutcome relation by Luft, Hunt, and Maerski (1987) reveal a significant, positive bilateral relationship for total hip replacement and hysterectomy. The "practice makes perfect" effect dominates for some acute conditions such as heart attack, where referral is less likely due to the emergency nature of the incident, as well as other conditions such as stomach and intestinal operations, which are usually managed by family physicians who may be insufficiently informed to guide patients to the best facilities. ${ }^{3}$ The "selective referral" effect dominates for aneurysms, prostatectomy, and CABG, procedures which are likely to be preceded by specialty consultations. Mukamel and Mushlin (1998) find that facilities with

there is substantial evidence that very low-volume operators obtain extremely poor results across a range of surgical procedures (e.g. Hughes, Hunt and Luft 1987, Cebul et al. 1998).

${ }^{3}$ Note that Hunt, Luft, and Maerski (1987) use data gathered in 1972 for the Professional Activities Study by the Commission on Professional and Hospital Activities (CPHA), as do many of the studies described in this section. Thus, hospital choice was far less restricted during the period explored in this body of literature than is the case today. 
superior CABG outcomes increased their market share relative to other facilities following the release of outcome data by the New York State Department of Health beginning in 1990. Finally, recent work by Ho (2002) extends the instrumental variables approach to hospital costs as well as industry learning-by-doing effects. Using data on angioplasties performed in California between 1984 and 1996, Ho finds evidence of hospital-specific as well as industrywide learning-by-doing, both for outcomes and for costs.

This paper does not attempt to enter the debate described above; however, the model outlined in section 3 borrows heavily from this literature. First, I use volume as an indicator of hospital quality, an assumption that reflects the "practice makes perfect" hypothesis. Second, I assume that patient demand responds to quality, the "selective referral" hypothesis. Finally, I require that hospitals are aware that volume begets volume, so they may consider strategies to increase their volume for competitive effect.

The prominence of procedure volume data in hospital marketing communications suggests that hospitals are indeed cognizant of this link. For example, the Cleveland Clinic website boasts, " [The] Cerebrovascular Center has one of the highest stroke-related patient volumes in North America. The Center treats over 2,000 cerebrovascular patients annually. High patient volumes provide our specialists with extensive experience, resulting in a team that routinely treats common problems and manages rare disorders much more frequently than smaller centers." A 2002 ad for Memorial Sloan-Kettering Cancer Center in The New York Times implores patients to "consider how much experience the hospital staff has in performing the specific procedures you need. Studies have demonstrated that, for many cancers, hospitals with a high volume of surgical cases had lower patient mortality and more positive patient outcomes than hospitals with lower volume." Organ transplant programs, cardiac surgery 
centers, and joint replacement services, among others, also emphasize procedure volumes in communications materials. In addition, medical associations, surgical accreditation boards, and the Centers for Medicare and Medicaid (CMS) provide procedure-specific volume guidelines for surgeons and/or hospitals. For example, Medicare will only cover liver transplants in centers that have performed 12 or more procedures per year for 3 consecutive years. ${ }^{4}$ The American College of Surgeons recommends at least 200 open-heart surgeries per hospital in order to "function efficiently" and attain quality goals. Finally, the growing body of volumeoutcome research and the resulting interest in regionalizing specialized procedures suggest that hospitals are likely to be aware of the volume-outcome-volume link.

\section{$2.2 \quad$ Strategic Entry Deterrence}

The theoretical literature on entry deterrence is well-developed (see Wilson (1992) in The Handbook of Game Theory for a good review). Within this literature, works on strategic preemption, characterized by incumbents' efforts to retain market dominance through irreversible investments, are most pertinent to the topic at hand. ${ }^{5}$ The critical insight from these models is that a sunk investment, be it in cost-cutting, capacity, advertising, or experience, credibly commits the incumbent to a particular course of action and therefore gives it an edge in strategic play. For example, an existing auto-assembly firm that builds a large new plant credibly commits to producing more vehicles in the event of entry (and perhaps in the absence of entry as well), thereby reducing the potential profits of an entrant and the

\footnotetext{
${ }^{4}$ Approval is site-specific, so a hospital cannot gain immediate approval by hiring a team of experienced surgeons.

${ }^{5}$ Wilson describes two additional broad categories of entry-deterrence models: signaling (or signal-jamming) models, in which incumbents convey (or block) information about their markets with the purpose of discouraging entry or promoting exit, and predation models, in which incumbents price aggressively to destroy the viability of an entrant.
} 
likelihood of entry.

Spence (1984) demonstrates the role of the learning curve, or accumulated experience, in erecting barriers to entry. Specifying a unit cost function that decreases in accumulated experience, Spence illustrates the cost advantage that accrues to early entrants. Spence and subsequent authors (e.g. Fudenberg and Tirole 1986) emphasize the difference between simple precommitment ("open loop") equilibria, in which the first mover recognizes the future cost savings associated with increased output in the current period, and perfect ("closed loop") equilibria, in which the first mover also considers the effect of current output on competitors' actions. In any given period, strategic considerations may lead firms to produce more or less than the open-loop optimum, depending on the exact nature of competition. In section 3, I present a simple model of quality competition among hospitals in which the closed-loop optimum implies overinvestment in production relative to the open-loop optimum.

The empirical literature on entry deterrence is rather sparse, with most studies documenting competitive responses to investment decisions rather than identifying strategic motives for the investments. Examples of such papers include Lieberman (1987), who finds that incumbents in concentrated chemical processing industries reduce investment in response to expansions by rivals, and Chevalier (1995), who finds that leveraged buyouts of supermarket chains are followed by softer product-market competition. Such studies suggest that capacity and capital structure are effective vehicles for strategic investment, but do not constitute prima facie evidence that such investment is taking place.

Two recent papers, Vogt (1999) and Ellison and Ellison (2000), construct specific tests for strategic preemption. Using data on adoption dates of magnetic resonance imaging (MRI) technology in 31 duopoly hospital markets, Vogt finds evidence of preemption through early 
adoption by a rival. Ellison and Ellison study the advertising, product presentation, and pricing behavior of pharmaceutical firms facing an immediate threat of generic entry due to patent expiration. Because the strategic incentive to deter entry is greatest in markets where entry is probable, as compared to markets where it is effectively blockaded (i.e. the drug has extremely small revenues) or extremely likely (e.g. Prozac), the authors look for investment behavior that is nonmonotonic in entry probability. They find evidence supportive of entry deterrence: incumbents in medium-sized markets are more likely than incumbents in small or large markets to decrease advertising and increase the variety of product presentations immediately prior to patent expiration. Both behaviors reduce the expected profits of an entrant, and should increase monotonically with market potential if entry deterrence motives are absent. This reasoning underlies the empirical tests I conduct in Section 4.

To summarize, the theoretical concepts tested in this paper are well-founded in the industrial organization literature. My contribution is to reformulate the models to reflect the unique features of the hospital industry, and in so doing to uncover a critical relationship between investment and volume that enables an empirical test of entry deterrence without data on the investments themselves. This paper also contributes to the fledgling empirical literature on strategic entry deterrence, applying a recently-developed identification strategy to a vital industry. 


\section{A Model of Entry Deterrence Through Learning-by-Doing}

\subsection{Assumptions}

In standard learning-by-doing models, firms that produce beyond the single-period optimum acquire more experience at the expense of current profits, since the increased production drives market price down. In hospital markets, however, supply and demand do not equilibrate contemporaneously via a price mechanism. The nation's largest insurer, Medicare, dictates a fixed price for each of roughly 500 Diagnosis Related Groups (DRGs), and private insurers negotiate reimbursement amounts with individual hospitals. Moreover, insured patients do not typically bear the marginal costs of treatment, as hospital stays generally exhaust deductibles and co-payment caps. A hospital seeking to expand current production in one of its product lines (say, cardiac surgery) must attract patients through other means: advertising, referral networks, amenities, and quality of care. Thus, price $P$ is not considered a choice variable for hospitals in this model; hospitals may, however, adjust any of the other variables. $^{6}$

A hospital can manipulate the other factors mentioned above, however, and I will aggregate these choices into a variable called quality, denoted by $L$. Quantity demanded for a given procedure in hospital $i$ at time $t$, denoted $Q_{t}^{i}$, is assumed to be an increasing function of hospital $i$ 's quality, and a decreasing function of the quality of its competitors $(-i)$ :

$$
Q_{t}^{i}=q\left(L_{t}^{i}, L_{t}^{-i}\right), \text { where } \frac{\partial q}{\partial L_{t}^{i}}>0 \text { and } \frac{\partial q}{\partial L_{t}^{-i}}<0
$$

\footnotetext{
${ }^{6}$ Note that the model is tested on Medicare data, and since Medicare beneficiaries face the same out-ofpocket price at all hospitals, a hospital cannot increase volume by lowering price.
} 
Although I have omitted procedure subscripts, all variables are at the procedure level, so that $L$ and $Q$ refer to quality and quantity for a particular procedure, respectively.

Learning-by-doing is incorporated in the production function for quality by including a term for accumulated experience. The other inputs into quality are jointly measured by the variable $K$, which can be loosely interpreted as current expenditure (on equipment, extra nurses, advertising, etc.). For simplicity, $K$ is not durable and expires at the end of each period. The production function for quality can therefore be written

$$
L_{t}^{i}=l\left(K_{t}^{i}, \bar{Q}_{t}^{i}\right), \text { where } \bar{Q}_{t}^{i}=\Sigma_{j=0}^{t-1} Q_{j}^{i}, \frac{\partial l}{\partial K_{t}^{i}}>0 \text { and } \frac{\partial l}{\partial \bar{Q}_{t}^{i}}>0
$$

The second argument in $l$ captures the "practice makes perfect" effect discussed in section 2 , as procedure quality is assumed to increase in a hospital's experience with the procedure. The "selective referral effect" is reflected in the function for quantity demanded, in that a hospital acquires more patients if it offers a higher quality level. Thus, volume begets more volume. The role of $K$ should not be understated, however, as it is the means by which a hospital produces quality upon entry, and also the only factor a hospital can adjust to rapidly increase quality, say in the face of an entry threat by a competitor. I further assume $\frac{\partial^{2} l}{\partial K^{2}}<0$ and $\frac{\partial^{2} q}{\left(\partial L^{i}\right)^{2}}<0$ to ensure a unique equilibrium.

For simplicity, the cost per procedure is fixed at $c$ and the cost per unit of $K$ is fixed at $r$. Finally, I assume the entrant incurs a cost $E$ upon entry, where $E$ is stochastic and its cumulative distribution function $F(E)$ is known to all parties. ${ }^{7}$

\footnotetext{
${ }^{7}$ Were $E$ not stochastic, the model would be deterministic: the $K_{1}^{M}$ needed to deter entry would be known, and entry-deterring investment would either be successful or would not be undertaken at all.
} 


\subsection{Model}

I begin with a standard 3-period strategic investment model, summarized in the following diagram:
$t=1$
$t=2$
$t=3$

Incumbent monopolist

chooses $K_{1}^{M}$ and

earns $\pi_{1}^{M}\left(K_{1}^{M}\right)$
Potential entrant

observes $Q_{1}^{M}\left(K_{1}^{M}\right)$

and the realization of $\mathrm{E}$

and decides whether

to enter
Monopoly payout $\pi_{2}^{* M}\left(K_{1}^{M}, K_{2}^{M^{*}}\right)$

or duopoly payouts

$\pi_{2}^{* D_{M}}\left(K_{1}^{M}, K_{2}^{D_{E}^{*}}, K_{2}^{D_{M}^{*}}\right)$

and

$\pi_{2}^{* D_{E}}\left(K_{1}^{M}, K_{2}^{D_{E}^{*}}, K_{2}^{D_{M}^{*}}\right)$

where the superscript $M$ refers to the monopolist when she is the sole supplier, and $D_{M}$ and $D_{E}$ to the former monopolist and the entrant, respectively, if entry occurs. The profit functions are assumed to be concave in $K$, and the payoffs in the event of entry result from a unique Nash equilibrium in the second-period game.

Assuming no discounting, the monopolist's maximization problem is simply

$$
\begin{aligned}
\max _{K_{1}^{M}, K_{2}^{M}, K_{2}^{D_{M}}} E(\pi)= & \pi_{1}^{M}\left(K_{1}^{M}\right)+F\left(\pi_{2}^{D_{E}}\left(K_{1}^{M}, K_{2}^{D_{E}}, K_{2}^{D_{M}}\right)\right) \cdot \pi_{2}^{D_{M}}\left(K_{1}^{M}, K_{2}^{D_{E}}, K_{2}^{D_{M}}\right)+ \\
& \left(1-F\left(\pi_{2}^{D_{E}}\left(K_{1}^{M}, K_{2}^{D_{E}}, K_{2}^{D_{M}}\right)\right)\right) \cdot \pi_{2}^{M}\left(K_{1}^{M}, K_{2}^{M}\right)
\end{aligned}
$$

The solution for $K_{2}$ is straightforward: the incumbent simply picks the optimal amount given the competitive environment, spending $K_{2}^{M^{*}}$ or $K_{2}^{D_{M}^{*}}$. The first-order condition for $K_{1}^{M}$ is

$$
\begin{aligned}
&-\frac{d \pi_{1}^{M}}{d K_{1}^{M}}= F\left(\pi_{2}^{D_{E}}\left(K_{1}^{M}, K_{2}^{D_{E}^{*}}, K_{2}^{D_{M}^{*}}\right)\right) \cdot \frac{\partial \pi_{2}^{D_{M}}}{\partial K_{1}^{M}}+\left(1-F\left(\pi_{2}^{D_{E}}\left(K_{1}^{M}, K_{2}^{D_{E}^{*}}, K_{2}^{D_{M}^{*}}\right)\right)\right) \cdot \frac{\partial \pi_{2}^{M}}{\partial K_{1}^{M}}+ \\
& F\left(\pi_{2}^{D_{E}}\left(K_{1}^{M}, K_{2}^{D_{E}^{*}}, K_{2}^{D_{M}^{*}}\right)\right) \cdot \frac{\partial \pi_{2}^{D_{M}}}{\partial K_{2}^{D_{E}}} \cdot \frac{d K_{2}^{D_{E}^{*}}}{d K_{1}^{M}}+ \\
& 12
\end{aligned}
$$




$$
\begin{aligned}
& \left(\pi_{2}^{D_{M}}\left(K_{1}^{M}, K_{2}^{D_{E}^{*}}, K_{2}^{D_{M}^{*}}\right)-\pi_{2}^{M}\left(K_{1}^{M}, K_{2}^{M^{*}}\right)\right) \cdot f\left(\pi_{2}^{D_{E}}\left(K_{1}^{M}, K_{2}^{D_{E}^{*}}, K_{2}^{D_{M}^{*}}\right)\right) . \\
& {\left[\frac{\partial \pi_{2}^{D_{E}}}{\partial K_{1}^{M}}+\frac{\partial \pi_{2}^{D_{E}}}{\partial K_{2}^{D_{M}}} \cdot \frac{d K_{2}^{D_{M}^{*}}}{d K_{1}^{M}}\right]}
\end{aligned}
$$

The term on the left-hand-side measures the cost associated with investment beyond the single-period optimum; because this investment pays off in future periods as well as in the current period, this term should be positive. The first two terms on the right-hand-side constitute the "open loop" or non-strategic first-order condition, in which the incumbent takes the entrant's behavior, including the probability of entry, as given. The third term is the "strategic entry accommodation" term, which incorporates the effect of the incumbent's investment decision in the first period on the entrant's choice of $K_{2}^{D_{E}}$. If it is greater (less) than zero, an incumbent that is accommodating entry in its market will overinvest (underinvest) in $K_{1}^{M}$ relative to the open-loop optimum. My focus is on the fourth term, the "strategic entry deterrence" effect.

The magnitude of the entry deterrence effect increases in the difference between monopoly and duopoly profits in the second period, as well as in the probability mass of $E$ at $\pi_{2}^{D_{E}}$. Intuitively, this means that the incentive to deter entry is greatest when substantial profits are at stake, and when the entrant is likely to be "on the fence" in terms of its entry decision. Under these circumstances, a bit of overinvestment has a large payoff. Because $\left(\pi_{2}^{D_{M}}-\right.$ $\left.\pi_{2}^{M}\right)$ is always negative and $f\left(\pi_{2}^{D_{E}}\right)$ is always positive, the sign of $\left[\frac{\partial \pi_{2}^{D_{E}}}{\partial K_{1}^{M}}+\frac{\partial \pi_{2}^{D_{E}}}{\partial K_{2}^{D_{M}}} \cdot \frac{d K_{2}^{D_{M}^{*}}}{d K_{1}^{M}}\right]$ determines whether the incumbent will overinvest or underinvest in order to deter entry. Under a broad set of conditions derived in Appendix A, this term is unambiguously negative, implying that the entry deterrence effect increases investment. 


\subsection{Generating Testable Predictions}

Using first-order conditions to discern the effect of entry deterrence motives on hospital investment decisions would be prohibitively difficult; not only would the researcher need exact profit, demand, and quality functions, she would also require hospital investment data at the procedure level. This section describes the two elements needed to transform the first-order condition into an empirically testable relationship.

First, I use a result derived in Ellison and Ellison (2000). The authors introduce a variable $z$ into the profit and cost functions for the incumbent and the potential entrant, where $z$ reflects market size or other characteristics associated with the probability of entry, and $\frac{d}{d z} \pi^{D_{E}^{*}}\left(K_{1}^{M}, K_{2}^{D_{E}}, K_{2}^{D_{M}}, z\right)>0$. They illustrate that, under certain conditions, the incumbent's investment is monotone increasing in $z$ in the absence of the entry-deterrence effect. (This situation would prevail, for example, if the incumbent's investment were not revealed to the entrant prior to the entry decision. $)^{8} \quad$ The conditions under which this proposition holds are not demanding, and a more thorough discussion is presented in Appendix B. Intuitively, this result simply means that in the absence of entry-deterrence motives, incumbents' investments will increase monotonically with market potential.

Having established monotonicity of investment in $z$ when entry-deterrence objectives are absent, the authors then illustrate nonmonotonicity when entry-deterrence objectives are present. This follows intuitively from an examination of the entry-deterrence term, now

\footnotetext{
${ }^{8}$ The first-order condition used to obtain $K_{1}^{M^{*}}$ in this case does incorporate the strategic entry accommodation term described above.
} 


$$
\begin{aligned}
& \left(\pi_{2}^{D_{M}}\left(K_{1}^{M}(z), K_{2}^{D_{E}^{*}}(z), K_{2}^{D_{M}^{*}}(z), z\right)-\pi_{2}^{M}\left(K_{1}^{M}(z), K_{2}^{M^{*}}(z), z\right)\right) . \\
& f\left(\pi_{2}^{D_{E}}\left(K_{1}^{M}(z), K_{2}^{D_{E}^{*}}(z), K_{2}^{D_{M}^{*}}(z), z\right)\right) \cdot\left[\frac{\partial \pi_{2}^{D_{E}}}{\partial K_{1}^{M}}+\frac{\partial \pi_{2}^{D_{E}}}{\partial K_{2}^{D_{M}}} \cdot \frac{d K_{2}^{D_{M}^{*}}}{d K_{1}^{M}}\right] .
\end{aligned}
$$

$f\left(\pi_{2}^{D_{E}}\right)$, the probability density of entrants who are indifferent between entering and not entering the market, does not increase monotonically in market attractiveness. When the market is extremely attractive or unattractive, few entrants will be indifferent; $f\left(\pi_{2}^{D_{E}}\right)$ will be largest when $\mathrm{z}$ has an intermediate value. Because $f\left(\pi_{2}^{D_{E}}\right)$ is multiplied by the difference between duopoly and monopoly profits, the strategic entry deterrence effect can be rather large, generating an investment curve that is nonmonotonic in $z$. In the surgical procedure setting, the prediction is that investment in $K_{1}^{M}$ will be greatest in markets where incumbents perceive entry to be possible, as compared to markets where entry is unlikely or likely. Figure 1 provides an illustration of such a pattern.

The second component needed to transform the incumbent's first-order condition into a testable relationship concerns $K_{1}^{M}$. Although $K_{1}^{M}$ is unobservable, the end product of the investment, first-period procedure volume $\left(Q_{1}^{M}\right)$, can be measured. Thus, changes in procedure volume, after controlling for covariates, can proxy for investment in quality. This result is a feature of the model sketched above; a profit-maximizing hospital would only spend money to boost quality if the quality improvement generated more business at the fixed price $P .{ }^{9}$ It is important to recognize, however, that learning-by-doing is the strategic investment vehicle in this model. An incumbent seeking to deter entry invests in quality in the first

\footnotetext{
${ }^{9}$ The result would be unaffected if quality itself had a positive weight in the hospital's objective function.
} 
period because the resulting increase in first-period volume increases quality in the second period.

To summarize, the prediction of interest is that incumbents with strong motives to deter entry will spend money to boost their quality in period 1 . This will increase the number of procedures they perform in period 1, raising their cumulative procedure volume and depressing the profits of a potential entrant in all subsequent periods. Because an increase in expenditure in period 1 translates directly into an increase in volume, I will use volume increases to study incumbents' investment behavior; I need not observe quality or expenditures. I will investigate whether incumbents in markets of intermediate attractiveness, where entry-deterring investment can have the greatest impact on the entry decision, exhibit the strongest volume growth in the face of shocks that increase industry profits.

\section{Testing the Model: The Market for Electrophysiological Studies}

\subsection{Market Selection}

To test these predictions empirically, I sought a surgical procedure that satisfied the key conditions dictated by the model: (1) a high degree of learning-by-doing; (2) a large fixed investment upon entry; (3) demand that is increasing in the quality of the procedure. In order to conduct a more rigorous test of the model, I further restricted my search to procedures that experienced positive profitability shocks. This setting enables me to explore both the cross-sectional prediction that markets with intermediate entry probabilities will demonstrate stronger volume growth than markets with low or high entry probabilities, and the time- 
series prediction that such markets will exhibit the most aggressive responses to a shock that heightens the threat of entry. Lastly, the procedure had to be well-represented among the elderly, as Medicare's inpatient database (MedPAR) is the only source of national longitudinal data with a sufficiently large sample size for my purposes. The procedure that best fulfills these criteria is electrophysiological study, or EP. ${ }^{10}$

Introduced in the early 1980s, EP is a highly-specialized invasive procedure to identify and possibly treat cardiac arrhythmias. The heart is stimulated at various rates and cadences, and electrode catheters placed within veins or arteries record the responses. Therapeutic ablation, in which tissue is destroyed using high-frequency currents, may also be performed. ${ }^{11}$ The Manual of Cardiovascular Medicine stresses the importance of a highly experienced operator in obtaining a successful outcome (criterion 1). Residents must complete 8 years of training before being permitted to assist in an EP. EP is performed in a speciallyequipped cardiac catheterization lab, which entails a large fixed entry cost (criterion 2). Patients are referred to EP by cardiologists, who should be aware of quality differentials among area hospitals (criterion 3). In addition, the procedure is well-represented in the Medicare population. Tabulations using California's census of hospital discharges (OSHPD) indicate that roughly half of EP procedures are performed on Medicare beneficiaries.

Although EP is extremely costly (hospitals reported expenses of $\$ 5,000$ to $\$ 21,000$ in 1988

\footnotetext{
${ }^{10}$ After identifying a comprehensive list of surgical procedures that experienced a sudden technological change or a large increase in Medicare reimbursement between 1984 and 1996, the period for which I have the MedPAR data, I reviewed medical literature and interviewed physicians to establish how well each procedure satisfies the technical criteria listed above. As a final screen, I used MedPAR data and data from California's state inpatient database to identify providers for each candidate procedure, rejecting those procedures that were performed in only a small number of markets during the pre-shock period (e.g. extracorporeal photopheresis, a cancer treatment in which a patient's blood is passed through an external device and exposed to ultraviolet light) or on a small number of Medicare patients (e.g. bone marrow transplants).

${ }^{11}$ The Miller-Keane Medical Dictionary; Manual of Cardiovascular Medicine (2000).
} 
dollars), it did not affect DRG assignment for several years. Patients undergoing EP were typically placed in DRGs 138 and 139 for cardiac arrhythmias, with 1988 reimbursements of roughly $\$ 1800$ and $\$ 2700$, respectively. At the beginning of 1989 , HCFA announced it was considering a reimbursement increase and established a new procedure code to determine the correct amount. Beginning in 1990, EP was designated a "non-OR procedure," placing recipients in higher-paying surgical DRGs. Reimbursements for these DRGs (104, 106, 108, and 112) ranged from $\$ 6,500$ to $\$ 26,700{ }^{12}$ Thus, the attractiveness of entry increased dramatically in 1990. In the context of the 3-period model, 1988 represents $t=1,1989$ is $\mathrm{t}=2$, and 1990 is $\mathrm{t}=3$. An incumbent's EP volume growth between 1988 and 1989 serves as a proxy for $K_{1}^{M}$.

Hospitals entering in $1990(\mathrm{t}=3)$ observe $K_{1}^{M}$ prior to making their entry decisions. Unfortunately, the real world operates in continuous time, so entry can and does occur in $\mathrm{t}=2$; this is a problem I address in the empirical analysis below.

\subsection{Data}

I obtain estimates of annual hospital EP volumes using a $20 \%$ sample of the 1985-1989 Medicare Provider Analysis and Review (MedPAR) files. This comprehensive data source contains information on all hospitalizations of Medicare enrollees, including surgical procedure codes and hospital identification numbers. ${ }^{13}$ The $20 \%$ sample comprises 2.1 to 2.8 million individual records per year. After aggregating the procedure data to the hospital level, each hospital is matched to a record from the 1988 Annual Survey of Hospitals by the American

\footnotetext{
${ }^{12}$ Estimates calculated by multiplying DRG weights by the standard hospital amount for large urban hospitals (Sources: 53 FR 38476, 54 FR 19636, 54 FR 36452). All years refer to HCFA's fiscal years, which begin in October of the preceding calendar year.

${ }^{13}$ Inpatient stays by HMO enrollees, who accounted for 5.2 percent of Medicare beneficiaries in 1990, are not included in the data.
} 
Hospital Association (AHA). This survey provides detailed information on virtually all US hospitals, including service offerings and utilization statistics.

Table 1 presents descriptive statistics for incumbent providers, defined as hospitals performing EP in 1988 and 1989. ${ }^{14}$ Between 1985 and 1989, the average incumbent's volume increased four-fold, reaching 35 procedures per year (recall that the data in Table 1 is a $20 \%$ sample). The mean value for the dependent variable, $\ln (1989$ volume $)-\ln (1988$ volume $)$, is .27, with substantial variation around this mean. Compared to the average US hospital, incumbent EP providers are more than twice as large and six times more likely to offer cardiac catheterization and open heart surgery.

Table 1 also reports market characteristics for the Hospital Service Areas in which incumbents are located, as defined by the Dartmouth Atlas of Health Care (1996). These HSAs were constructed by assigning each zip code to the HSA where the greatest proportion of its Medicare residents was hospitalized in 1992 and 1993. There are 3,436 HSAs in the United States, with population ranging between 866 (Hoven, South Dakota) and 2.7 million (Chicago); of these, 149 had EP incumbents in 1988. On average, incumbents faced 1.5 competitors in 1988. There were 96 HSAs with monopolist incumbents (therefore contributing 96 hospital-level observations), 28 with two incumbents (56 hospital-level observations), and 25 with three or more incumbents (95 hospital-level observations).

\footnotetext{
${ }^{14}$ Of the 252 incumbent providers, I exclude four that stopped performing EP in 1989, and one that could not be matched to a Hospital Service Area.
} 


\subsection{Empirical Analysis}

\subsubsection{Cross-sectional analysis}

To investigate whether volume growth is nonmonotonic in entry probability, I begin with a cross-sectional analysis, in which I regress $\ln (1989$ volume $)-\ln (1988$ volume $)$ for every incumbent on a measure of the ex ante entry probability in that incumbent's HSA. While the ex post entry probability for HSAs with similar characteristics can be calculated from the data, it is endogenous to incumbents' investment decisions. For example, if hospitals facing an intermediate ex ante threat of entry succeed in increasing volume and deterring entrants, the ex post entry probability for such hospitals would be lower than the actual ex ante threat. As a result, I estimate ex ante entry probability as the number of potential entrants in the incumbent's HSA, rather than using actual entry data to predict these probabilities, as is done in Ellison and Ellison (2000). I define a potential entrant as a non-incumbent hospital with cardiac catheterization and open heart surgery facilities. ${ }^{15}$ A catheterization lab is a prerequisite to establishing an EP service, while open heart surgery is a complement and safety backup for EP.

Table 2 reports descriptive statistics on the number of potential and actual entrants. ${ }^{16}$ 103 out of 247 incumbent providers are located in HSAs without any potential entrants (as defined above), and the ex-post probability of entry for hospitals in these markets is correspondingly low (9 percent). The ex-post probability of entry reaches nearly one-half for

\footnotetext{
${ }^{15}$ Children's hospitals and federal government hospitals are not counted as potential entrants; none of the incumbents falls into these categories.

${ }^{16}$ Of the 423 providers that performed EP for the first time in 1989 or 1990, I exclude 5 due to missing data and 11 that exited in 1989. I also drop 91 providers that performed fewer than 3 procedures during the entire period for which I have the data, 1985-1996. This restriction minimizes the number of hospitals labeled as entrants solely due to coding errors.
} 
hospitals facing one potential entrant, jumps to 85 percent for hospitals with two potential entrants, and declines slightly for hospitals in markets with three or more potential entrants. Thus, the ex-ante measure of entry probability accords well with the ex-post realization, and if hospitals are behaving strategically, investment should peak in markets with one potential entrant. Indeed, Figure 2, which graphs unadjusted incumbent growth rates against the number of potential entrants, mirrors the theoretical pattern in Figure 1.

To control for other factors that may be contributing to this pattern, I estimate specifications of the following form:

$$
\begin{aligned}
\ln (1989 \text { volume })_{m h}-\ln (1988 \text { volume })_{m h}= & \alpha+\sum_{i=1}^{4} \beta_{i} I(\text { potential entrants }=i)_{m} \\
& +\left[\varphi Z_{m}+\nu X_{h}\right]+\varepsilon_{m h} .
\end{aligned}
$$

The dependent variable is the continuous growth rate for hospital $h$ in market $m$. Using the growth rate rather than the absolute change in volume accounts for differences in the size of individual hospitals' programs; an increase of 5 procedures represents a larger investment for a program initially performing 10 procedures per year than for a program performing 50 . The independent variables of interest are the indicator variables for the number of potential entrants, with zero as the omitted category. Because these variables vary at the HSA level, all standard errors are corrected for correlation within HSAs. $\quad$ A finding of $\widehat{\beta}_{1}>\widehat{\beta}_{4+}$ constitutes conclusive evidence of entry deterrence; as Figure 1 illustrates, such a result requires an extremely strong entry deterrence effect. If the underlying monotonic relationship between volume growth and entry probability is steep or convex, hospitals facing intermediate 
entry probabilities will not exhibit significantly higher growth than hospitals subject to high entry probabilities, even in the presence of entry-deterring investment. Because the omitted category represents a low entry probability, absent any controls all of the coefficients in $\widehat{\beta}$ should be greater than zero.

Caution must be exercised when including additional controls, as these controls may be collinear with market attractiveness, precisely the factor the potential entrant indicators are meant to capture. $X_{h}$ is a vector of hospital-level controls, consisting of all of the variables reported in Table 1: years of EP experience, ownership status, teaching status, indicator for catheterization lab and open heart surgery facilities, annual number of surgical operations, and number of beds. $Z_{h}$ is a vector of market-level controls, including population and its square, the EP penetration rate (=number of EP procedures/population), the EP "access rate" (=number of incumbents/population), and an indicator for entry in $1989(\mathrm{t}=2)$. If a market experiences entry in 1989 , incumbents did not have a full year to expand their programs prior to the entry decision, so their investment levels may be depressed relative to those of hospitals in markets that did not experience such entry. Because entry at any time is likeliest in markets with multiple potential entrants, the results may be biased in favor of nonmonotonicity in the absence of a control for such entry. All other control variables are measured as of 1988, with the exception of population, which is only available for 1990 .

Column 1 of Table 3 presents estimates of $\beta$ from the most parsimonious specification, which excludes all control variables. Column 2 adds hospital controls, column 3 adds the indicator for entry in 1989, and column 4 adds all the remaining market control variables. In all four specifications, a nonmonotonic investment pattern is evident, with the largest coefficient on $I$ (potential entrants=1). Incumbents in these markets increased their procedure 
volumes approximately 30 percentage points more than did incumbents in markets with no potential entrants, and 21 to 45 percentage points more than incumbents in markets with 4 or more potential entrants. As predicted, all coefficients are positive in the first specification. $\widehat{\beta}_{1}$ is statistically significant at $\mathrm{p}<.05$ in columns 1 and 2 , and $\mathrm{p}<.10$ in column 3 . The coefficient on entry in 1989 is positive rather than negative, implying that early entry does not bias the results in favor of nonmonotonicity. While the hospital control variables have little impact on $\widehat{\beta}$, the full set of HSA controls reduces the magnitude of these estimates, and in particular the magnitude of $\widehat{\beta}_{1}-\widehat{\beta}_{4+}$. Because the potential entrant indicators vary at the HSA level, the HSA controls are likely collinear with these regressors. Regardless, the general nonmonotonic pattern of the point estimates is robust to this full set of controls. Overall, the results in Table 3 are suggestive of entry deterrence, with $\widehat{\beta}_{1}>\widehat{\beta}_{4}$ in all specifications. However, the coefficient estimates are too imprecise to reject $\widehat{\beta}_{1}=\widehat{\beta}_{4+}$ at conventional levels of significance for 2 of the 4 specifications.

As with all cross-sectional analyses, a primary concern is the possibility that omitted factors are driving the results. These concerns are mitigated in this setting because the omitted factors would have to vary nonmonotonically with volume growth or market attractiveness in order to produce a bias. Nevertheless, the possibility remains that markets with one potential entrant are fast-growing for reasons other than entry-deterring investment. To address this possibility, I reformulate the regression specification to control for different growth trends across market types (where "type" refers to the number of potential entrants) prior to the profitability shock in 1989 . 


\subsubsection{Panel Analysis}

To control for preexisting differences in growth rates across market types, I assemble a panel dataset of EP volumes for each provider between 1985 and 1989, and estimate

$$
\begin{aligned}
\ln (\text { volume })_{m h t}= & \alpha+\sum_{i=1}^{4} \beta_{i} I(\text { potential entrants }=i)_{m}+\delta_{t}+ \\
& \sum_{i=1}^{4} \mu_{i} I(\text { potential entrants }=i)_{m} \bullet \text { year }_{t}+ \\
& \sum_{i=1}^{4} \gamma_{i} I(\text { potential entrants }=i)_{m} \bullet I(1989)_{t}+ \\
& \rho I(\text { entrant })_{m t}+\varphi Z_{m}+\nu X_{h}+\varepsilon_{m h t},
\end{aligned}
$$

where $\delta_{t}$ is a set of year dummies, $\sum_{i=1}^{4} \mu_{i} I$ (potential entrants $\left.=i\right)_{m} \bullet$ year ${ }_{t}$ is a set of trends for each market type, $I(1989)_{t}$ is an indicator variable for the "treatment" year, 1989, and $I$ (entrant) $m t$ is an indicator variable for entry in an incumbent's HSA in year $t$ (with this exception, all the variables in $X_{h}$ and $Z_{m}$ are unchanged from the cross-sectional analysis). $\gamma$ captures the extra growth in 1989 by market type, controlling for trends by market type, time-invariant differences associated with hospital and market characteristics (of which type is one), and any shock associated with a new entrant. Column 1 of Table 4 presents the estimates of $\gamma$ from this specification. The specifications in columns 2 and 3 are more stringent, with market fixed effects in place of $Z_{m}$ in column 2 and hospital fixed effects in place of $Z_{m}$ and $X_{h}$ in column 3. (Hospital fixed effects obviate the need for market fixed effects, as the latter consist of groups of the former.)

The coefficient estimates in Table 4 reveal that incumbents in markets with a single potential entrant increased their volume 46-48 percentage points more between 1988 and 1989 
than did incumbents in markets with no potential entrants, after controlling for differences in growth trends across market types. This finding is robust to the inclusion of market or hospital fixed effects. Moreover, in the specifications with fixed effects, $\widehat{\beta}_{1}=\widehat{\beta}_{4+}$ can now be rejected in favor of $\widehat{\beta}_{1}>\widehat{\beta}_{4+}$ at the $\alpha<.10$ level.

Because the incentive to invest strategically existed in all years, these results constitute strong evidence of entry deterrence: even controlling for pre-1989 differences in market growth rates, hospitals in markets with intermediate entry probabilities boosted their procedure volumes following the reimbursement announcement more than did hospitals of any other market type.

\subsubsection{Monopolist Incumbents}

The analyses presented thus far include all incumbents, regardless of market structure. Theoretically, the results should be stronger if the sample is restricted to monopolist incumbents. First, monopolist incumbents do not have the incentive to free-ride off the entry-deterring investments of rivals. Second, monopolists stand to lose more rents from private payers if entry occurs than do incumbent duopolists or oligopolists (the efficiency effect). Table 2 contains descriptive statistics on the number of potential and actual entrants in these markets. Tables 5 and 6 present the cross-sectional and panel analyses, respectively, for the 96 monopolist incumbents.

The results are strongly consistent with a priori expectations. For each specification, $\widehat{\beta}_{1}$ is larger in this sample than in the sample of all incumbents. Due to the small sample

sizes and correspondingly large standard errors, however, the differences between the $\widehat{\beta}_{1}$ for the two samples are not statistically significant. Direct comparisons between estimates of 
$\beta_{1}-\beta_{4+}$ cannot be made because the small number of monopolist markets with multiple

potential entrants necessitates a single category $(2+)$, but $\widehat{\beta}_{1}-\widehat{\beta}_{2+}$ is consistently large and positive, and occasionally statistically significant.

\subsubsection{Did It Work?}

Although the volume growth I document need not have succeeded in deterring entry in order to have been ex ante optimal, evidence of this kind would vindicate the strategy. One naive test for examining the effectiveness of this strategy is to compare the actual entry incidence experienced by hospitals with strong 1988-89 growth (i.e. those that attempted to deter entry) with that by hospitals with weaker 1988-89 growth, focusing exclusively on markets with one potential entrant. Unfortunately, the hospitals that made large investments during this period are not randomly selected; it is likely that these are the most successful and aggressive providers, and hence entry into their markets may be lower for this reason.

This bias notwithstanding, the data imply that strong growth is associated with a higher probability of entry. Table 8 reports data on the 1989 residuals from the panel regression with hospital fixed effects (Table 4, column 3). These residuals measure the extent to which individual hospitals departed from the growth trends within their respective potential entrant categories, controlling for year and hospital fixed effects as well as the effect of new entry within the HSA. The data indicate that in markets with one potential entrant - where entrydeterring investments appear to have been made - hospitals with unusually strong growth experienced more entry than did hospitals with weaker growth. Thus, entrants appear to have interpreted incumbents' volume growth not as a barrier to entry but rather as a signal of market potential. 
Although this naive test suggests entrants were undeterred by incumbents' actions, such a conclusion is premature. In addition to the binary entry decision, entrants' choice of product characteristics must be considered. To the extent that entrants differentiated themselves from incumbents (i.e. by becoming low-quality, low-cost providers) as a result of incumbents' investments, entry deterrence may have succeeded.

\section{Conclusion}

Hospital behavior is difficult to study using traditional methods. The obfuscation of the pricing mechanism and the difficulty in measuring quality necessitate a creative approach to uncovering all actions, let alone strategic ones. Entry into new services is one of the few clear indicators of hospital decisions, and has therefore attracted attention in the health economics and industrial organization literatures. Although several researchers have investigated the reduced-form relationship between Herfindahl-type measures of hospital competition and

service offerings (e.g. the "medical arms race" literature), few have studied strategic interactions among players in local hospital markets.

In this paper, I focus on one of the most important and accessible measures of quality at the procedure level, hospital volume, and ask whether hospitals invest in volume for the purpose of deterring entry. The recent proliferation of self-proclaimed "centers of excellence" may be a formalization of this strategy. By combining simple models of patient demand, quality production, and differentiated product market competition, I am able to generate clear theoretical predictions regarding entry deterrence through volume growth. The main result is that procedure growth rates should increase monotonically in market attractiveness 
unless hospitals engage in entry-deterring investment. Such investment should be largest where entry deterrence is likeliest to impact entry decisions: in markets of intermediate attractiveness. When the entry deterrence incentive is sufficiently strong, these markets will grow at significantly faster rates than markets with either low or high market potential, simply because incumbents in these markets have a greater expected payoff for investments that are observed by potential entrants prior to making their entry decisions.

I test this model using hospital-level data on electrophysiological studies (EP), an invasive cardiac procedure developed in the 1980s. I find that hospitals facing an intermediate probability of entry generated the strongest volume growth in the year following an announced reimbursement increase for EP. This increase cannot be attributed to time-invariant omitted variables, as it is present even after controlling for hospital fixed effects, nor to pre-existing differences in growth trends, as it is robust to the inclusion of trends for each probability group. In the most stringent specifications, the volume growth in intermediate markets is statistically significantly greater than that in low and high markets.

This research provides support for the hypothesis that hospitals manipulate surgical volume for strategic effect. In addition to revealing the sophistication of hospital decisionmaking, this result contributes to the mounting evidence that the Hippocratic oath does not suffice to protect patients from undergoing unnecessary but profitable treatments. One mitigating factor in this case is that entry deterrence through learning-by-doing will result in greater specialization across hospitals and superior outcomes for patients, ceteris paribus. More generally, stronger competition in quality will reduce the need for regulatory interventions such as "certificates of need," which are designed to constrain the number of providers of a given service in order to improve quality and reduce duplicative costs. However, these 
benefits must be weighed against the increased market power that remaining providers will be able to exercise in the private market. A more thorough analysis of the welfare effects of entry deterrence in surgical procedure markets, while beyond the scope of this paper, is an important next step for future research. 


\section{References}

Cebul, Randall et al., 1988, "Indications, Outcomes, and Provider Volumes for Carotid Endarterectomy," JAMA 279 (16): 1282-1287.

Center for the Evaluative Clinical Sciences, Dartmouth Medical School, 1996, The Dartmouth Atlas of Health Care(Chicago: American Hospital Publishing).

Chernew, Michael, Gautam Gowrisankaran, and Mark Fendrick, 2002, "Payer Type and the Returns to Bypass Surgery: Evidence from Hospital Entry Behavior," The Journal of Health Economics 21 (3): 451-474.

Chevalier, Judith, 1995, "Capital Structure and Product Market Competition: Empirical Evidence from the Supermarket Industry," American Economic Review 85: 415-435.

Dixit, A., 1979, "A Model of Duopoly Suggesting a Theory of Entry Barriers," Bell Journal of Economics 10: 20-32.

Dixit, A., 1980, "The Role of Investment in Entry Deterrence," Economic Journal 90: 95-106.

Fudenberg, D. and J. Tirole, 1983, "Learning by Doing and Market Performance," Bell Journal of Economics 14: 522-530.

Fudenberg, D. and J. Tirole, 1986, Dynamic Models of Oligopoly (London:Harwood).

Ellison, Glenn, and Sara Fisher Ellison, 2000, "Strategic Entry Deterrence and the Behavior of Pharmaceutical Incumbents Prior to Patent Expiration," mimeo, MIT Department of Economics.

Henkel, John, 1998, "Prostate Cancer: No One Answer for Testing or Treatment," FDA Consumer September-October.

Ho, Vivian, 2002, "Learning and the Evolution of Medical Technologies: The Diffusion of Coronary Angioplasty," The Journal of Health Economics 21 (5): 873-885.

Hughes, Robert, Sandra Hunt, and Harold Luft, 1987, "Effects of Surgeon Volume and Hospital Volume on Quality of Care in Hospitals," Medical Care 25 (6).

Lieberman, Marvin, 1987, "Post Entry Investment and Market Structure in the Chemical Processing Industry," RAND Journal of Economics 18: 533-549.

Luft, Harold, Sandra Hunt, and Susan Maerski, 1987, "The Volume-Outcome Relationship: Practice-Makes-Perfect or Selective-Referral Patterns?" Health Services Research 22 (2): 157-182.

Mukamel, Dana, and Alvin Mushlin, 1998, "Quality of Care Information Makes a Difference," Medical Care 36, No. 7: 945-954. 
Newhouse, John, 1982, The Sporty Game (New York: Knopf).

Smiley, Robert, 1988, "Empirical Evidence on Strategic Entry Deterrence," International Journal of Industrial Organization 6: 167-180.

Spence, A. M., 1977, "Entry, Capacity, Investment and Oligopolistic Pricing," Bell Journal of Economics 8: 534-544.

Spence, Michael, 1979, "Investment Strategy and Growth in a New Market," Bell Journal of Economics 10: 1-19.

Spence, Michael, 1981, "The Learning Curve and Competition," Bell Journal of Economics 12: $49-70$.

Spence, Michael, 1984, "Cost Reduction, Competition, and Industry Performance," Econometrica 52: 101-122.

Stanford, J.L., et al., 1999, "Prostate Cancer Trends 1973-1995," SEER Program, National Cancer Institute, NIH Publication No. 99-4543. Bethesda, MD, 1999.

Steinwald, Bruce and Laura A. Dummit, 1989, "Hospital Case-Mix Change: Sicker Patients or DRG Creep?" Health Affairs 8: 35-47.

Tirole, Jean, 1997, The Theory of Industrial Organization (Cambridge: The MIT Press).

U.S. Census Bureau, Administrative and Customer Services Division, Statistical Compendia Branch, 2001, Statistical Abstract of the United States.

Wilson, Robert, 1992, "Strategic Models of Entry Deterrence," in R.J. Aumann and S. Hart, eds., The Handbook of Game Theory (Elsevier Science Publishers), Chapter 1.

Vogt, William B., 1999, "Detecting Strategic Behavior in Technology Adoption: the Example of Magnetic Resonance Imaging," mimeo, Heinz School, Carnegie Mellon University.

von Stackelberg, H., 1934, Marketform und Gleichgewicht (Vienna: Julius Springer).

Zwanziger, Jack and Glenn A. Melnick, 1988, "The Effects of Hospital Competition and the Medicare PPS Program on Hospital Cost Behavior in California," The Journal of Health Economics 7: 301-320. 
Figure 1. Predicted Incumbent Investment Patterns

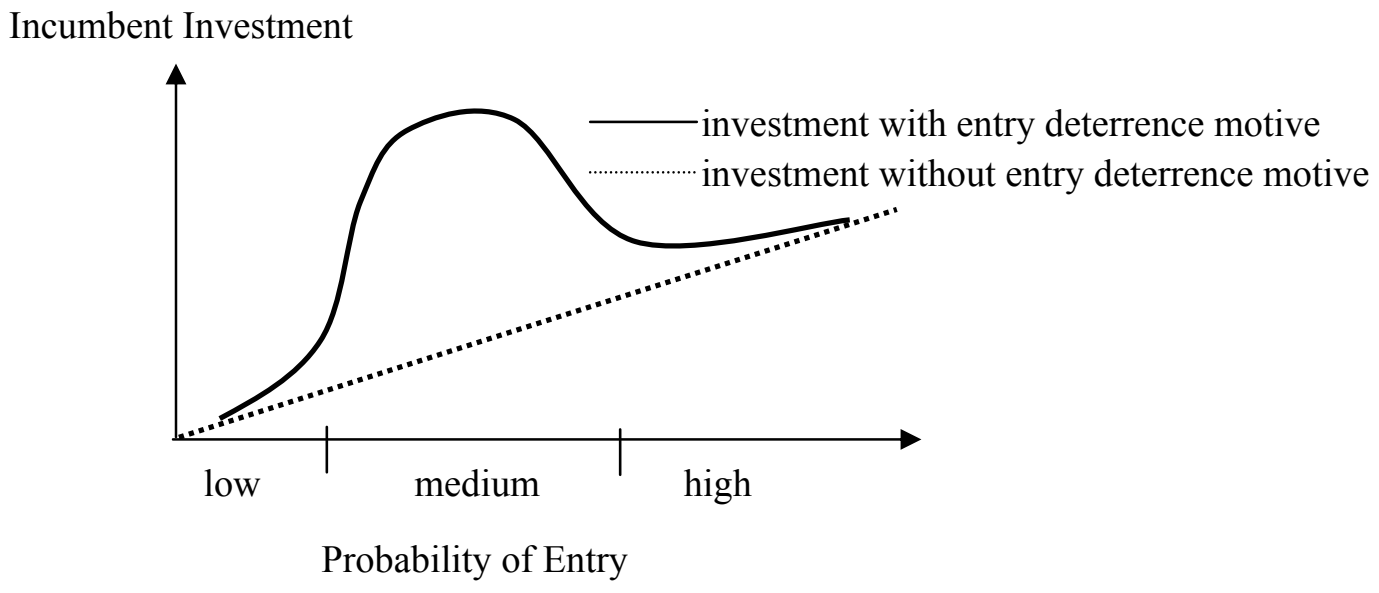

Figure 2. Actual Incumbent Volume Growth, EP Market

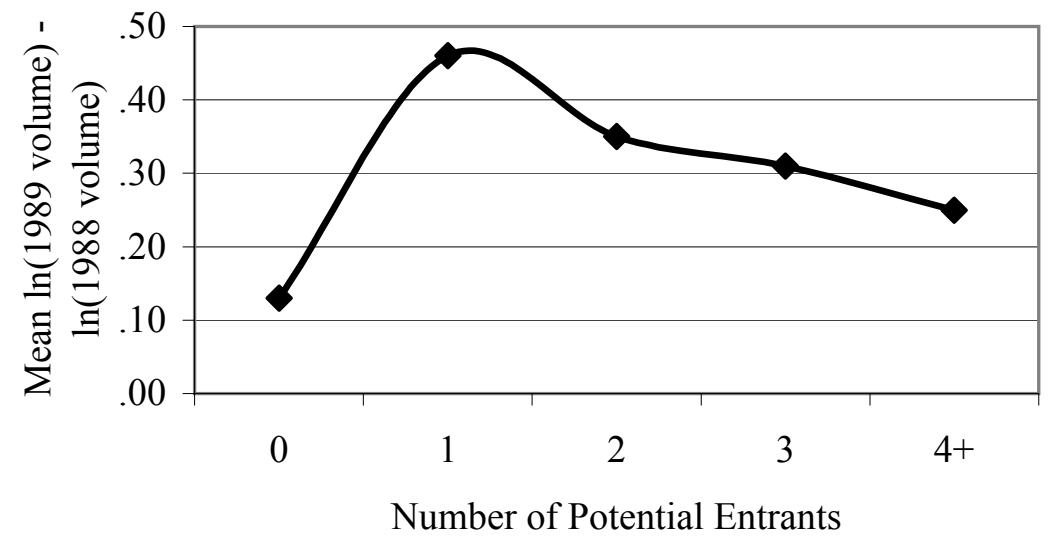


Table 1: Descriptive Statistics, EP Incumbents $(\mathrm{N}=\mathbf{2 4 7})$

\begin{tabular}{|c|c|c|}
\hline & Mean & Standard Deviation \\
\hline \multicolumn{3}{|l|}{ Hospital Characteristics } \\
\hline 1985 volume & 1.56 & $(3.54)$ \\
\hline 1986 volume & 2.01 & $(3.72)$ \\
\hline 1987 volume & 2.91 & $(4.12)$ \\
\hline 1988 volume & 5.11 & $(5.35)$ \\
\hline 1989 volume & 6.99 & $(7.14)$ \\
\hline $\ln (1989$ volume $)-\ln (1988$ volume $)$ & .27 & $(.87)$ \\
\hline Years of EP experience by 1988 & 2.67 & $(1.21)$ \\
\hline For-proft & .05 & $(.22)$ \\
\hline Government-owned & .13 & $(.34)$ \\
\hline Not-for-profit & .82 & $(.39)$ \\
\hline Teaching hospital & .53 & $(.50)$ \\
\hline Cath lab and open heart surgery & .87 & $(.34)$ \\
\hline Annual surgical operations & 7852 & $(4458)$ \\
\hline Beds & 517 & $(250)$ \\
\hline \multicolumn{3}{|l|}{ Market (HSA) Characteristics } \\
\hline Number of incumbents & 2.47 & $(1.76)$ \\
\hline Number of potential entrants & 1.34 & $(1.70)$ \\
\hline Entry in 1989 & .22 & $(.42)$ \\
\hline Entry in 1990 & .28 & $(.45)$ \\
\hline Entry in 1989 or 1990 & .43 & $(.50)$ \\
\hline Population & 7.49 & $(6.24)$ \\
\hline EP penetration rate & 17.68 & $(23.07)$ \\
\hline EP access rate & .60 & $(.52)$ \\
\hline
\end{tabular}

Notes:

(1) Markets are Health Service Areas (HSAs) as defined in the Dartmouth Atlas (1996).

(2) Potential entrants are non-incumbent hospitals with catheterization labs and open heart surgery facilities, located in the incumbent's HSA.

(3) Population isgiven for 1990 and measured in 100,000s.

(4) EP penetration rate $=($ number of 1988 procedures in the HSA*5)/population.

(5) $\mathrm{EP}$ access rate $=$ number of incumbents in HSA/HSA population

Sources: 20\% MedPAR sample 1985-1989, AHA 1988, Dartmouth Atlas (1996). 
Table 2. Ex-Ante and Ex-Post Entry Measures, All Incumbents

\begin{tabular}{ccc}
\hline Number of Potential Entrants & $\mathrm{N}$ & Ex-post probability of entry \\
\hline 0 & 103 & .09 \\
1 & 61 & .49 \\
2 & 34 & .85 \\
3 & 26 & .77 \\
$4+$ & $\underline{23}$ & .78 \\
All & 247 & .43 \\
\hline
\end{tabular}

Notes:

(1) The unit of observation is the hospital.

(2) Number of potential entrants is the number of non-incumbent hospitals with catheterization labs and open heart surgery facilities in the incumbent's HSA.

(3) Ex-post entry probability is the mean value of an indicator for entry in the incumbent's HSA. 
Table 3: Cross-Sectional Results, All Incumbents

\begin{tabular}{|c|c|c|c|c|}
\hline & \multicolumn{4}{|c|}{ Dependent Variable is $\ln (1989$ volume $)-\ln (1988$ volume $)$} \\
\hline \multicolumn{5}{|c|}{ Number of Potential Entrants } \\
\hline \multirow[t]{2}{*}{1} & $.330 * *$ & $.354 * *$ & $.299 *$ & .170 \\
\hline & $(.150)$ & $(.149)$ & $(.157)$ & $(.157)$ \\
\hline \multirow[t]{2}{*}{2} & .218 & .138 & .038 & -.082 \\
\hline & $(.163)$ & $(.178)$ & $(.191)$ & $(.224)$ \\
\hline \multirow[t]{2}{*}{3} & .173 & .176 & .062 & -.018 \\
\hline & $(.219)$ & $(.230)$ & $(.236)$ & $(.249)$ \\
\hline \multirow[t]{2}{*}{$4+$} & .120 & -.006 & -.149 & .012 \\
\hline & $(.221)$ & $(.208)$ & $(.196)$ & $(.237)$ \\
\hline \multicolumn{5}{|c|}{$\begin{array}{l}\text { Test of } H_{0}: \text { coeff }(\text { pot. entrants }=1)=\text { coeff }(\text { pot. entrants }=4+) ; H_{1}: \text { coeff }(\text { pot. entrants }=1)> \\
\text { coeff }(\text { pot. entrants }=4+) . \text { P-values are reported. }\end{array}$} \\
\hline & .19 & .05 & .02 & .26 \\
\hline \multicolumn{5}{|l|}{ Control Variables } \\
\hline Hospital Controls & $\mathrm{N}$ & Y & Y & $\mathrm{Y}$ \\
\hline$[$ F-test $]$ & & {$[.00]$} & {$[.00]$} & {$[.02]$} \\
\hline HSA Controls & $\mathrm{N}$ & $\mathrm{N}$ & $\mathrm{N}$ & $\mathrm{Y}$ \\
\hline$[$ F-test $]$ & & & & {$[.00]$} \\
\hline \multirow[t]{2}{*}{ Entry in 1989} & & & .288 & .152 \\
\hline & & & $(.168)$ & $(.159)$ \\
\hline $\mathrm{N}$ & 247 & 245 & 245 & 245 \\
\hline
\end{tabular}

$\underline{\text { Notes }}$

(1) Hospital controls include ownership type, teaching status, cath lab/open heart surgery dummy, number of beds, number of surgical operations, and years of EP experience (between 1985 and 1988).

(2) HSA controls include population, population squared, EP penetration rate, and EP access rate.

(3) Robust standard errors corrected for correlation within HSAs are in parentheses.

(4) * signifies $\mathrm{p}<.10, * *$ signifies $\mathrm{p}<.05, * * *$ signifies $\mathrm{p}<.01$ 
Table 4. Panel Results, All Incumbents, 1985-89

\begin{tabular}{cccc}
\hline & \multicolumn{3}{c}{ Dependent Variable is $\ln$ (volume) } \\
\hline Number of Potential Entrants*I(1989) & & & \\
1 & $.455 * * *$ & $.459 * *$ & $.483 * *$ \\
\multirow{2}{*}{2} & $(.172)$ & $(.189)$ & $(.201)$ \\
& .264 & .189 & .248 \\
3 & $(.171)$ & $(.199)$ & $(.221)$ \\
& .247 & .220 & .208 \\
$4+$ & $(.268)$ & $(.294)$ & $(.320)$ \\
& .110 & .023 & .047 \\
\hline
\end{tabular}

Test of $H_{0}$ : coeff(pot. entrants $\left.=1\right) * I(1989)=$ coeff $($ pot. entrants $=4+) * I(1989)$;

$H_{1}$ : coeff(pot. entrants $\left.=1\right) * I(1989)>$ coeff $($ pot. entrants $=4+) * I(1989)$. P-values are reported.

\begin{tabular}{lrrr} 
& \multicolumn{1}{c}{.13} & .10 & .10 \\
\hline Year Fixed Effects & $\mathrm{Y}$ & $\mathrm{Y}$ & $\mathrm{Y}$ \\
Number of Potential Entrants Fixed Effects & $\mathrm{Y}$ & $\mathrm{N} / \mathrm{A}$ & $\mathrm{N} / \mathrm{A}$ \\
Number of Potential Entrants Trends & $\mathrm{Y}$ & $\mathrm{Y}$ & $\mathrm{Y}$ \\
Hospital Controls & $\mathrm{Y}$ & $\mathrm{Y}$ & $\mathrm{N} / \mathrm{A}$ \\
[F-test] & {$[.00]$} & {$[.00]$} & \\
HSA Controls & $\mathrm{Y}$ & $\mathrm{N} / \mathrm{A}$ & $\mathrm{N} / \mathrm{A}$ \\
[F-test] & {$[.00]$} & & \\
Entry dummy & .034 & -.026 & .031 \\
& $(.057)$ & $(.060)$ & $(.068)$ \\
HSA Fixed Effects & $\mathrm{N}$ & $\mathrm{Y}$ & $\mathrm{N} / \mathrm{A}$ \\
Hospital Fixed Effects & $\mathrm{N}$ & $\mathrm{N}$ & $\mathrm{Y}$ \\
N & 849 & 849 & 856 \\
\hline
\end{tabular}

$\underline{\text { Notes }}$

(1) Hospital controls include ownership type, teaching status, cath lab/open heart surgery dummy, number of beds, number of surgical operations, and years of EP experience (between 1985 and 1988).

(2) HSA controls include population, population squared, EP penetration rate, and EP access rate.

(3) Entry dummy equals 1 in any year in which there is entry in the incumbent's HSA (except when the incumbent is the entrant)

(4) Robust standard errors corrected for correlation within HSAs are in parentheses.

(5) * signifies $\mathrm{p}<.10, * *$ signifies $\mathrm{p}<.05, * * *$ signifies $\mathrm{p}<.01$ 
Table 5. Ex-Ante and Ex-Post Entry Measures, Monopolist Incumbents

\begin{tabular}{ccc}
\hline Number of Potential Entrants & $\mathrm{N}$ & Ex-post probability of entry \\
\hline 0 & 58 & 0.09 \\
1 & 22 & 0.36 \\
$2+$ & $\underline{16}$ & $\underline{0.94}$ \\
All & 96 & .29 \\
\hline
\end{tabular}

Notes:

(1) The unit of observation is the hospital, which is the same as the HSA in this case.

(2) Number of potential entrants is the number of non-incumbent hospitals with catheterization labs and open heart surgery facilities in the incumbent's HSA. 
Table 6: Cross-Sectional Results, Monopolist Incumbents

\begin{tabular}{|c|c|c|c|c|}
\hline & \multicolumn{4}{|c|}{ Dependent Variable is $\ln (1989$ volume $)-\ln (1988$ volume $)$} \\
\hline \multicolumn{5}{|c|}{ Number of Potential Entrants } \\
\hline \multirow[t]{2}{*}{1} & $.421 *$ & $.542 * *$ & $.518 * *$ & .210 \\
\hline & $(.237)$ & $(.256)$ & $(.258)$ & $(.287)$ \\
\hline \multirow[t]{2}{*}{$2+$} & .302 & .350 & .120 & -.394 \\
\hline & $(.209)$ & $(.233)$ & $(.225)$ & $(.376)$ \\
\hline \multicolumn{5}{|c|}{$\begin{array}{l}\text { Test of } H_{0}: \text { coeff }(\text { pot. entrants }=1)=\text { coeff }(\text { pot. entrants }=2+) ; H_{1}: \text { coeff }(\text { pot. entrants }=1) \\
>\text { coeff }(\text { pot. entrants }=2+) . P \text {-values are reported. }\end{array}$} \\
\hline & .33 & .24 & .06 & .01 \\
\hline \multicolumn{5}{|l|}{ Control Variables } \\
\hline Hospital Controls & $\mathrm{N}$ & Y & Y & Y \\
\hline [F-test $]$ & & {$[.07]$} & {$[.02]$} & {$[.03]$} \\
\hline HSA Controls & $\mathrm{N}$ & $\mathrm{N}$ & $\mathrm{N}$ & Y \\
\hline [F-test $]$ & & & & {$[.00]$} \\
\hline \multirow[t]{2}{*}{ Entry in 1989} & & & $.531 * *$ & .359 \\
\hline & & & $(.255)$ & $(.234)$ \\
\hline $\mathrm{N}$ & 96 & 95 & 95 & 95 \\
\hline
\end{tabular}

$\underline{\text { Notes }}$

(1) Hospital controls include ownership type, teaching status, cath lab/open heart surgery dummy, number of beds, number of surgical operations, and years of EP experience (between 1985 and 1988).

(2) HSA controls include population, population squared, EP penetration rate, and EP access rate.

(3) Robust standard errors corrected for correlation within HSAs are in parentheses.

(4) * signifies $\mathrm{p}<.10, * *$ signifies $\mathrm{p}<.05, * * *$ signifies $\mathrm{p}<.01$ 
Table 7. Panel Results, Monopolist Incumbents, 1985-89

\begin{tabular}{ccc}
\hline & \multicolumn{2}{c}{$\begin{array}{c}\text { Dependent Variable is } \\
\ln \text { (volume) }\end{array}$} \\
\hline Number of Potential Entrants*I(1989) & & \\
1 & $.530^{*}$ & $.627 *$ \\
\multirow{2}{*}{$2+$} & $(.278)$ & $(.330)$ \\
& .291 & .275 \\
& $(.245)$ & $(.289)$ \\
\hline
\end{tabular}

Test of $H_{0}$ : coeff $($ pot. entrants $=1) * I(1989)=$ coeff $($ pot .

entrants $=2+) * I(1989) ; H_{1}:$ coeff(pot. entrants $\left.=1\right) * I(1989)>$ coeff $($ pot.

entrants $=2+) * I(1989)$. $P$-values are reported.

\begin{tabular}{lrr} 
& .22 & .17 \\
\hline Year Fixed Effects & $\mathrm{Y}$ & $\mathrm{Y}$ \\
Number of Potential Entrants Fixed Effects & $\mathrm{Y}$ & $\mathrm{N} / \mathrm{A}$ \\
Number of Potential Entrants Trends & $\mathrm{Y}$ & $\mathrm{Y}$ \\
Hospital Controls & $\mathrm{Y}$ & $\mathrm{N} / \mathrm{A}$ \\
[F-test] & {$[.00]$} & \\
HSA Controls & $\mathrm{Y}$ & $\mathrm{N} / \mathrm{A}$ \\
[F-test] & {$[.00]$} & \\
Entry dummy & .096 & .080 \\
& $(.143)$ & $(.151)$ \\
Hospital=HSA Fixed Effects & $\mathrm{N}$ & $\mathrm{Y}$ \\
$\mathrm{N}$ & 326 & 331 \\
\hline
\end{tabular}

$\underline{\text { Notes }}$

(1) Hospital controls include ownership type, teaching status, cath lab/open heart surgery dummy, number of beds, number of surgical operations, and years of EP experience (between 1985 and 1988).

(2) HSA controls include population, population squared, EP penetration rate, and EP access

(3) Entry dummy equals 1 in any year in which there is entry in the incumbent's HSA (except when the incumbent is the entrant)

(4) Robust standard errors corrected for correlation within HSAs are in parentheses.

(5) * signifies $\mathrm{p}<.10,{ }^{* *}$ signifies $\mathrm{p}<.05, * * *$ signifies $\mathrm{p}<.01$ 
Table 8. Incidence of Entry In Markets With One Potential Entrant

\begin{tabular}{cccc}
\hline $\begin{array}{c}\text { Quartile of Investment } \\
\text { Residual }\end{array}$ & $\mathrm{N}$ & $\begin{array}{c}\text { Range of Investment } \\
\text { Residual }\end{array}$ & Incidence of Entry \\
\hline 1 & 16 & $(-1.07,-.42)$ & .25 \\
2 & 15 & $(-.42,-.02)$ & .47 \\
3 & 15 & $(-.02, .39)$ & .60 \\
4 & 15 & $(.39,1.22)$ & .66 \\
\hline
\end{tabular}

Note:

Investment residuals are 1989 residuals for hospitals facing one potential entrant, calculated using the model reported in column 3, Table 4 . 


\section{Appendix A}

To sign the entry deterrence term,

$\left(\pi_{2}^{D_{M}}\left(K_{1}^{M}, K_{2}^{D_{E}^{*}}, K_{2}^{D_{M}^{*}}\right)-\pi_{2}^{M}\left(K_{1}^{M}, K_{2}^{M^{*}}\right)\right) \cdot f\left(\pi_{2}^{D_{E}}\left(K_{1}^{M}, K_{2}^{D_{E}^{*}}, K_{2}^{D_{M}^{*}}\right)\right) \cdot\left[\frac{\partial \pi_{2}^{D_{E}}}{\partial K_{1}^{M}}+\frac{\partial \pi_{2}^{D_{E}}}{\partial K_{2}^{D_{M}}} \cdot \frac{d K_{2}^{D_{M}^{*}}}{d K_{1}^{M}}\right]$

I begin with the entrant's problem: $\max _{K_{2}^{D_{E}}}[P-c] q\left(l\left(K_{2}^{D_{E}}, 0\right), l\left(K_{2}^{D_{M}}, Q_{0}+q\left(l\left(K_{1}^{M}, Q_{0}\right)\right)\right)\right)-$ $r K_{2}^{D_{E}}$, where 0 reflects the entrant's cumulative experience upon entry and $Q_{0}$ reflects the incumbent's cumulative experience prior to period 1. The first-order condition is $q_{1}\left(l\left(K_{2}^{D_{E}^{*}}, 0\right), l\left(K_{2}^{D_{M}}, Q_{0}+q\left(l\left(K_{1}^{M}, Q_{0}\right)\right)\right)\right) \cdot l_{1}\left(K_{2}^{D_{E}^{*}}, 0\right)=\frac{r}{[P-c]}$, where $q_{1}$ denotes the derivative of $q$ with respect to the first argument, and $l_{1}$ is similarly defined. Given the assumptions in the text, $\frac{\partial \pi_{2}^{D_{E}^{*}}}{\partial K_{1}^{M}}=[P-c] q_{2} l_{2} q_{1} l_{1}<0$ and $\frac{\partial \pi_{2}^{D_{E}^{*}}}{\partial K_{2}^{D_{M}}}=[P-c] q_{2} l_{1}<0$. The intuition for these signs is simply that better quality on the part of a competitor erodes profits in a differentiated-products setting.

To sign $\frac{d K_{2}^{D_{M}^{*}}}{d K_{1}^{M}}$, I solve the incumbent's second-period problem in the face of entry, $\max _{K_{2}^{D_{M}}}[P-c] q\left(l\left(K_{2}^{D_{M}}, Q_{0}+q\left(l\left(K_{1}^{M}, Q_{0}\right)\right)\right), l\left(K_{2}^{D_{E}}, 0\right)\right)-r K_{2}^{D_{M}}$. The optimal $K_{2}^{D_{M}^{*}}$ satisfies $q_{1}\left(l\left(K_{2}^{D_{M}^{*}}, Q_{0}+q\left(l\left(K_{1}^{M}, Q_{0}\right)\right)\right), l\left(K_{2}^{D_{E}}, 0\right)\right) \cdot l_{1}\left(K_{2}^{D_{M}^{*}}, Q_{0}+q\left(l\left(K_{1}^{M}, Q_{0}\right)\right)\right)=\frac{r}{[P-c]}$. The total differential of this expression with respect to $K_{1}^{M}$ is $\left[q_{11}\left(l_{1} \frac{d K_{2}^{D_{M}^{*}}}{d K_{1}^{M}}+l_{2} q_{1} l_{1}\right)+q_{12} l_{1} \frac{d K_{2}^{D_{E}^{*}}}{d K_{1}^{M}}\right] \cdot l_{1}+$ $\left[l_{11} \frac{d K_{2}^{D_{M}^{*}}}{d K_{1}^{M}}+l_{12} q_{1} l_{1}\right] \cdot q_{1}=0$. Thus, the set of additional conditions under which $\frac{d K_{2}^{D_{M}^{*}}}{d K_{1}^{M}}>0$ is:

(1) Inputs into quality are complementary $\left(l_{12}>0\right)$ and

(2a) Demand is separable in own quality and competitor's quality: $q_{12}=0$ and $\frac{d K_{2}^{D_{E}^{*}}}{d K_{1}^{M}}=0$ or (2b) Quality choices are strategic complements $\left(q_{12}>0\right)$ and $\frac{d K_{2}^{D_{E}^{*}}}{d K_{1}^{M}}>0$ or

(2c) Quality choices are strategic substitutes $\left(q_{12}<0\right)$ and $\frac{d K_{2}^{D_{E}^{*}}}{d K_{1}^{M}}<0$. 
The intuition for $\frac{d K_{2}^{D_{M}^{*}}}{d K_{1}^{M}}>0$ is that the marginal product of $K_{2}^{D_{M}}$ increases with first-period volume, which in turn is an increasing function of $K_{1}^{M}$.

Under the above conditions, the entry deterrence term is unambiguously negative, implying that the monopolist will overinvest in $K_{1}^{M}$ to deter entry.

\section{Appendix B}

This appendix summarizes the monotonicity result presented in Ellison and Ellison (2000), as applied to the model outlined in section 3. A more precise exposition can be found in the original source.

Without entry-deterrence motives, the first-order condition for $K_{1}^{M^{*}}(z)$ is

$$
-\frac{d \pi_{1}^{M}}{d K_{1}^{M}}=F\left(\pi_{2}^{D_{E}^{*}}\left(K_{1}^{M}(z), z\right)\right) \cdot \frac{\partial \pi_{2}^{D_{M}^{*}}}{\partial K_{1}^{M}}+\left(1-F\left(\pi_{2}^{D_{E}^{*}}\left(K_{1}^{M}(z), z\right)\right)\right) \cdot \frac{\partial \pi_{2}^{M^{*}}}{\partial K_{1}^{M}}
$$

The strategic entry accommodation effect is already incorporated in the choice of $K_{1}^{M}(z)$ (compare with the first-order condition in section 3.2 , where $\frac{\partial \pi_{2}^{D_{M}}}{\partial K_{1}^{M}}$ are $\frac{\partial \pi_{2}^{M}}{\partial K_{1}^{M}}$ used).

Differentiating this expression with respect to z yields

$$
\begin{aligned}
-\frac{d^{2} \pi_{1}^{M}}{d z d K_{1}^{M}}-\frac{d^{2} \pi_{1}^{M}}{d\left(K_{1}^{M}\right)^{2}} \cdot \frac{d K_{1}^{M^{*}}}{d z}= & F\left(\pi_{2}^{D_{E}^{*}}\right) \cdot\left(\frac{\partial^{2} \pi_{2}^{D_{M}^{*}}}{\partial\left(K_{1}^{M}\right)^{2}} \cdot \frac{d K_{1}^{M^{*}}}{d z}+\frac{\partial^{2} \pi_{2}^{D_{M}^{*}}}{\partial z \partial K_{1}^{M}}\right) \\
& +\left(1-F\left(\pi_{2}^{D_{E}^{*}}\right)\right) \cdot\left(\frac{\partial^{2} \pi_{2}^{M^{*}}}{\partial\left(K_{1}^{M}\right)^{2}} \cdot \frac{d K_{1}^{M^{*}}}{d z}+\frac{\partial^{2} \pi_{2}^{M^{*}}}{\partial z \partial K_{1}^{M}}\right) \\
& +f\left(\pi_{2}^{D_{E}^{*}}\right) \cdot \frac{d \pi_{2}^{D_{E}^{*}}}{d z} \cdot\left(\frac{\partial \pi_{2}^{D_{M}^{*}}}{\partial K_{1}^{M}}-\frac{\partial \pi_{2}^{M^{*}}}{\partial K_{1}^{M}}\right)
\end{aligned}
$$


Solving for $\frac{d K_{1}^{M^{*}}}{d z}$ produces

$$
\begin{aligned}
& {\left[F\left(\pi_{2}^{D_{E}^{*}}\right) \cdot\left(\frac{\partial^{2} \pi_{2}^{D_{M}^{*}}}{\partial z \partial K_{1}^{M}}\right)+\left(1-F\left(\pi_{2}^{D_{E}^{*}}\right)\right) \cdot\left(\frac{\partial^{2} \pi_{2}^{M^{*}}}{\partial z \partial K_{1}^{M}}\right)+\frac{d^{2} \pi_{1}^{M}}{d z d K_{1}^{M}}\right]} \\
& \frac{d K_{1}^{M^{*}}}{d z}=\frac{+f\left(\pi_{2}^{D_{E}^{*}}\right) \cdot \frac{d \pi_{2}^{D_{E}^{*}}}{d z} \cdot\left[\frac{\partial \pi_{2}^{D_{M}^{*}}}{\partial K_{1}^{M}}-\frac{\partial \pi_{2}^{M^{*}}}{\partial K_{1}^{M}}\right]}{-\frac{d^{2} \pi_{1}^{M}}{d\left(K_{1}^{M}\right)^{2}}-F\left(\pi_{2}^{D_{E}^{*}}\right) \cdot \frac{\partial^{2} \pi_{2}^{D_{M}^{*}}}{\partial\left(K_{1}^{M}\right)^{2}}-\left(1-F\left(\pi_{2}^{D_{E}^{*}}\right)\right) \cdot \frac{\partial^{2} \pi_{2}^{M^{*}}}{\partial\left(K_{1}^{M}\right)^{2}}}
\end{aligned}
$$

Due to the concavity assumptions for the profit functions, the denominator of this expression is always positive. Given the earlier assumption of $\frac{d \pi_{2}^{D_{E}^{*}}}{d z}>0, K_{1}^{M^{*}}(z)$ is monotone nondecreasing (nonincreasing) in $\mathrm{z}$ if both bracketed terms in the numerator are nonnegative (nonpositive). Ellison and Ellison label the first term the "direct effect" of $z$ on $K_{1}^{M^{*}}$; it is positive if increasing $z$ raises marginal profits more than it raises marginal investment costs. The second bracketed term is the "competition effect," which is nonnegative if the marginal duopoly profits associated with an additional unit of $K_{1}^{M^{*}}$ exceed or equal the marginal monopoly profits. Note that if demand is separable in $L^{i}$ and $L^{-i}$, the competition effect drops out. 